\title{
Student Achievement Differences as a Function of Principal Longevity
}

\author{
Hafedh Azaiez and John R. Slate \\ Department of Educational Leadership, Sam Houston State University, Huntsville, United States \\ Email: hxa019@shsu.edu
}

\begin{abstract}
In this study, differences in reading and mathematics performances based on principal longevity at the same campus were examined. Data were obtained from the Early Childhood Longitudinal Study-Kindergarten Class of 1998-1999 (ECLS-K) surveys in which information was collected from parents, teachers, and principals. Data were collected from 9,196 campuses across the United States. For purposes of this investigation, information from only the principal component of the ECLS-K was analyzed. For both reading and mathematics, inferential analyses revealed the presence of statistically significant differences based on principal tenure. Students at campuses where principals had six or more years of experience at that campus had statistically significantly higher average reading and mathematics performance than at campuses where principals had less than six years of experience at that campus. School district officials responsible for principal assignment and transfer may consider these findings when making decisions about changing principal's placement.
\end{abstract}

Keywords: Student achievement, principal experience, school leadership, ECLS-K.

\section{Introduction}

As school district leaders across the country focus on enhancing student achievement, district leaders concentrate their effort in selecting the most effective principal for each campus. In fact, numerous research studies (e.g., Borg \& Slate, 2014; Nettles \& Petscher, 2006; Huff et al., 2011) exist in which the effects of principal leadership, longevity, and turnover on campus overall performance have been addressed. Huff et al. (2011) examined the relationship of principal tenure and experience in education on middle school student achievement. Principal stability was correlated to student achievement. In addition, the data revealed major support to hire and retain leaders with several years of experience (Huff et al., 2011). In another study, Miller (2013) investigated the relationship between principal turnover and student achievement in North Carolina public schools. Initially, schools that had a change of principals experienced a decrease in student academic performance. However, student academic achievement increased in most cases the year following the installation of the new principal. Nevertheless, Miller (2013) concluded that principal replacement occurs typically after several years of poor student achievement scores. Therefore, more studies are needed to determine the relationship between student performance and principal turnover.

In one such study, Mascall and Leithwood (2010) analyzed the influence of principal turnover on schools and sought to identify strategies to minimize its possible negative effects. They determined that principal turnover usually has a negative influence on student achievement, some school leaders managed to maintain or prevent decline in student achievement. However, they were unable to improve it (Mascall \& Leithwood, 2010). School districts should develop a plan to keep principals for a duration of a minimum of 4 years at the same school. In addition, Mascall and Leithwood (2010) concluded that school district leaders should encourage, support, and ensure the presence of leadership distribution in each campus to help with transition with principal turnover transition. In a similar investigation, Fink and Brayman (2006) conducted several case studies in different schools to determine the relationship between school leadership succession and educational change. One interesting finding was that the turnover of principals in most schools had accelerated in recent years. For example, one campus had four principals in 28 years, then three principals in the last 5 years. They concluded that rapid turnover of principals can generate obstacles to educational change because teachers and parents view principals as key players for bringing change. Therefore, Fink and Brayman (2006) suggested creating succession 
plans and processes into all school improvement plans to help with the school leadership transition and maintain sustainability.

School district leaders across the United States are attempting and experimenting with different ways and methods to increase principal retention and decreasing principal turnover. Consequently, researchers are examining and assessing their success by conducting several studies. For instance, Papa (2007) investigated the factors that might influence attracting and retaining highly effective principals. Principals who were more than 46 years old were more likely to remain at the same campus than younger principals. In addition, principals were more likely to leave schools with higher percentages of at-risk students and less-qualified teachers for smaller schools with higher percentages of White and nonLimited English Proficient students. However, principals were more likely to agree to work at a campus with a more challenging situation if they were compensated with an increase in salary (Papa, 2007). As such, Papa (2007) recommended a policy initiative to provide funding to offer a subsidy for principals willing to work in disadvantaged schools. On the other hand, Pijanowski and Brady (2009) conducted a quantitative study to examine if salary can influence attracting and retaining school leaders in state of Arkansas. In fact, the authors were attempting to determine the variance in compensation at each step of the career ladder for prospective administrators. The salary difference between a high school principal and midcareer high school teacher was about $\$ 46,640$ or a $97.5 \%$ increase in annual salary. Pijanowski and Brady (2009) concluded that salary was not the primarily cause of the principal shortage. However, the increase in salary does not compensate for the increase of stress and working conditions for school administrators. They suggested that policymakers create ways to decrease the stress level and increase the support for principals. Farley-Ripple, Raffel, and Welch (2012) attempted to identify the factors that influenced school administrator decisions to make career paths changes and transition to improve recruitment and retention efforts. Administrators made these career move because they were promoted, reassigned, recruited, removed, requested, self-initiated, or tapped. Farley-Ripple et al. (2012) indicated that administrators usually decide to make a career path move because they felt confident about the current role and therefore looked for new challenge, whereas, administrators who felt supported by the district decided to stay in their current assignment.

Partlow and Ridenour (2008) investigated the frequency of principal turnover in Ohio and its effects on schools. Schools that had one or two principals in a 7 -year period were $57.3 \%$ urban, $80.8 \%$ suburban, and $60 \%$ in rural schools. On the other hand, schools that had three or more principals in the same period were $42.7 \%$ urban, $19.2 \%$ suburban, and $40.1 \%$ rural. Therefore, Partlow and Ridenour (2008) suggested that the frequency of principal changes in urban schools was statistically significantly higher than in suburban schools. Partlow and Ridenour (2008) concluded that urban and rural schools demonstrated lower stability than suburban schools. Similarly, Baker, Punswick, and Belt (2010) investigated school leadership turnover and stability in Missouri. One of the most striking findings is that at a given starting time, about half of the principals were no longer principals in the state after 5 years and almost $75 \%$ of the principals made at least one change to another campus. Baker et al. (2010) concluded that salary influenced principals whether to stay or move to another campus. In fact, principals with higher salaries than their colleagues had a greater chance to remain longer at their assigned campus. Therefore, Baker et al. (2010) recommended a differentiated pay model for principals to help distribute highly effective principals across the school district. Finally, Tekleselassie and Villarreal (2011) completed a three-level generalized multilevel model study to determine principals' intentions for career mobility and changes. They determined that salary was strongly correlated to principal intention of leaving or remaining at the same campus. Tekleselassie and Villarreal (2011) suggested that age and gender were related to mobility intention. For example, female principals were more committed to remain at the same campus whereas younger principals were more inclined to make a career move than older ones. Thus, providing principals with supervision autonomy and job enthusiasm encouraged them to remain at the same campus.

\subsection{Purpose}

Given that reading and mathematics performance are the two most important components for determining the success or failure of a campus based on state and federal accountability measures, an imperative exists to determine the factors that are possibly related to student achievement in reading and mathematics. The purpose of this study was to examine the extent to which reading and 
mathematics performance were related to principal years of experience. Through analyzing a national dataset, relevant information may be uncovered and may be used by school district in making future principal's hiring and placement decisions.

\section{Background}

Several scholars such as Waters and Marzano discussed the evolving role of the principal and principal's influence on the success or the failure of a campus (Borg \& Slate, 2014; Nettles \& Petscher, 2006; Marzano, Waters, \& McNulty, 2005). In fact, the influence of school leaders may be second only to classroom teaching when it comes to influencing student achievement (Borg \& Slate, 2014). The school principal is the creator or re-shaper of a school's teacher culture and influences not only the actions of the school staff, as well as their motivations and spirit (Deal \& Peterson, 1999). In fact, campus principals have an essential direct or indirect influence on teachers' performance, job satisfaction, effectiveness, motivation, commitment to professional development, and collaboration. Thus, the principal is the most influential person in the success or the failure of a campus because she/he is responsible for recruiting, training, retaining highly effective teachers. The principal is also responsible for creating and carrying the vision of a campus. Highly effective teachers usually are attracted to strong and highly effective leaders. However, across the nation, school districts struggle to recruit, train, and retain highly effective principals especially with turn-around campuses. Many school district leaders have increased principal's starting salaries to stay competitive with other school districts and created a performance pay or retention bonus to attract and retain the best principals available in the region. However, fewer principals are remaining at the same campus for several years for a variety reasons.

\subsection{Significance of the Study}

A considerable number of research studies exist in which the crucial role of the principal on the success of a campus and student achievement has been examined (Borg \& Slate, 2014; Nettles \& Petscher, 2006; Marzano et al., 2005). However, fewer researchers such as Partlow and Ridenour (2008) have focused on the effect of principal longevity on student performances in reading and mathematics. In fact, most of the researchers concentrated on a particular subset of principals located in a particular state within the United States. On the other hand, the findings of this study may be generalized across the entire United States, such as would be possible through the use of a national dataset. In addition, findings may have practical implications for school district officials when it comes to making principal's transfer and assignment. Finally, school district leaders and educational policy makers may be motivated to examine ways and incentives to increase principal retention and thus, minimize principal turnover.

\subsection{Research Questions}

The following research questions were addressed in this study: (a) What is the difference in the reading achievement as a function of principal experience? and (b) What is the difference in the mathematics achievement as a function of principal experience?

\section{Method}

\subsection{Participants}

Utilized as the unit of analysis for this study was public and private school administrators of campuses across the United States. Principal, head of school, or other administrator was asked to complete the survey for Early Childhood Longitudinal Study- Kindergarten Class 1998-1999 (ECLS-K) in the spring 2004 (National Center for Education Statistics, 2006). The number of public and private school administrators who completed the administrator survey in the Spring of 2004 equaled 9,196. They voluntarily completed the ECLS-K questionnaire. 


\subsection{Instrumentation and Procedures}

The ECLS-K self-administered questionnaire was intended to collect information about the school, student performance in reading and math, teachers, school climate, as well as demographic characteristics of the school's principal of headmaster. The ECLS-K School Administrator Questionnaire was administrated in Spring 2004. School administrators were asked to record the percentage of students who scored at or above grade level in reading and mathematics. Another important question was for school administrators to list their years of experience as a school administrator at their current campus.

\section{$4 \quad$ Results}

Prior to conducting an inferential statistical procedure to answer the research questions, the underlying assumptions of data normality were checked. An examination of the standardized skewness coefficient (i.e., the skewness value divided by the standard error of the skewness) and standardized kurtosis coefficient (i.e., the kurtosis value divided by the standard error of the kurtosis) for the first research question revealed serious departures from normality for the dependent variable, reading achievement. With respect to the second research question, the standardized skewness coefficient and standardized kurtosis coefficient for the second research question revealed serious departures from normality for the dependent variable, students' achievement in mathematics.

Because student achievement in reading was not normally distributed, a nonparametric (i.e., MannWhitney's $U$ ) independent samples $t$-test was used to determine whether student reading achievement differed by principal years of experience. An independent samples $t$-test was an appropriate inferential statistical procedure to use because the independent variable (i.e., years of experience) was dichotomous and the dependent variable (i.e., reading achievement) was at the interval/ratio level of measurement (Slate \& Rojas-LeBouef, 2011). The Mann-Whitney $U$ test revealed a statistically significant difference in the reading performance, $U=11757912.00, p<.001$, Cohen's $d$ of 0.22 , by principal years of experience. Using Cohen's (1988) criteria, this finding represented a small effect size. Reading achievement at campuses where principals had six or more years' experience was statistically significantly higher, 7.67 points higher, than campuses where principals had five or less years' experience. Delineated in Table 1 are the descriptive statistics for reading achievement for campuses as a function of principal longevity.

Table 1. Descriptive statistics for reading performance by principal years of experience

\begin{tabular}{l|c|c|c}
\hline Years of Experience & $n$ & $M$ & $S D$ \\
\hline 1-5 Years & 5,933 & 45.39 & 36.47 \\
\hline 6 or more Years & 3,263 & 53.08 & 34.40 \\
\hline
\end{tabular}

Regarding the second research question, the Mann-Whitney $U$ test revealed a statistically significant difference in the reading and mathematics performances, $U=11835223.00, p<.001$, Cohen's $d$ of 0.23 , by principal years of experience. Using Cohen's (1988) criteria, this finding represented a small effect size. Campuses with higher principal longevity had a statistically significantly higher mathematics achievement, 8.30 points higher, than campuses with principal longevity of five or less years. Readers are directed to Table 2 for the descriptive statistics for this analysis.

Table 2. Descriptive statistics for mathematics performance by principal years of experience

\begin{tabular}{l|c|c|c}
\hline Years of Experience & $n$ & $M$ & $S D$ \\
\hline 1-5 Years & 5,933 & 44.35 & 36.63 \\
\hline 6 or more Years & 3,263 & 52.66 & 34.63 \\
\hline
\end{tabular}




\section{Discussion}

The principal plays a pivotal role in student achievement (Borg \& Slate, 2014). In this study, student achievement in reading and mathematics was examined as a function of principal years of experience. Statistically significant differences exist in the percentage of students who were at or above grade level in reading and mathematics. Students attending schools where principals had six or more years of experience at that campus scored statistically significantly better in reading and in mathematics than did their peers who were enrolled in schools where principals had fewer than six years of experience at that school. Small effect sizes were present for all results. These findings are aligned with findings in the literature that it takes three to five years for principals to create substantial change at a campus (Huff et al., 2011). In fact, they need to be given enough time to influence campus culture and student achievement (Hall \& Hord, 2001).

Leadership in school has undergone many changes and reforms over time. State and federal requirements for meeting accountability standards are higher than ever. For instance, the new State of Texas Assessments of Academic Readiness was implemented in spring 2012 and the passing standards are increasing each year. Thus, federal and state legislation has directly influenced academic decisions. District officials are struggling to recruit, develop, and retain highly effective principals to ensure that every campus is meeting accountability requirements. In addition, school district leaders make quick decisions to move one successful principal from one campus to another hoping to duplicate success. In fact, due the increase in accountability standards, principals are only allowed one to two years to turn around or transform a campus. Then, they are quickly removed or transferred to another campus. The finding of this study may be interpreted to mean that principals should be provided with more time to improve student achievements. School district leaders need to develop strategies to retain principals for more than six years at the same school campus and to provide them with the needed resources so that they can improve their students' academic performance.

Several variables are present that may explain the student achievement results such the percentage of students on free or reduced lunch, mobility rate, and student demographics. In fact, the percentage of students on free or reduced lunch can mask the effect of principal experience. Other questions that could addressed in future research could be: (a) What is the difference in the reading achievement as a function of principal experience for Title 1 schools? (b) What is the difference in the mathematics achievement as a function of principal experience for Title 1 schools? (c) What is the difference in the reading achievement as a function of principal experience for a non-Title 1 school? and (d) What is the difference in the mathematics achievement as a function of principal experience for a non-Title 1 school? In summary, based on the finding of this study, students who attended schools where principals had experience of six or more years at that campus were more likely to have higher reading and mathematics scores than students who were enrolled in schools where principals had less than six years of experience at that campus.

\section{References}

1. Baker, B. D., Punswick, E., \& Belt, C. (2010). School leadership stability, principal moves, and departures: Evidence from Missouri. Educational Administration Quarterly, 46(4), 523-557. doi:10.1177/0013161X10383832.

2. Borg, D., \& Slate, J. R. (2014). Principals' leadership emphases as a function of school performance. Frontiers in Education, 2(1), 1-5.

3. Cohen, J. (1988). Statistical power analysis for the behavioral sciences (2nd ed.). Hillsdale, NJ: Lawrence Erlbaum.

4. Deal, T. E., \& Peterson, K. D. (1999). Shaping school culture: The heart of leadership. San Francisco, CA: Jossey-Bass.

5. Farley-Ripple, E. N., Raffel, J. A., \& Welch, J. C. (2012). Administrator career paths and decision processes. Journal of Educational Administration, 50(6), 788-816. doi:10.1108/09578231211264694.

6. Fink, D., \& Brayman, C. (2006). School leadership succession and the challenges of change. Educational Administration Quarterly, 42(1), 62-89. doi:10.1177/0013161X05278186. 
7. Hall, G., \& Hord, S. (2001). Implementing change: Patterns, principles, and potholes. Needham Heights, MA: Allyn and Bacon.

8. Huff, T. S., Brockmeier, L. L., Leech, D. W., Martin, E. P., Pate, J. L., \& Siegrist, G. (2011). Principal and school-level effects on student achievement. National Teacher Education Journal, 4(2), 67-79.

9. Mascall, B., \& Leithwood, K. (2010). Investing in leadership: The district's role in managing principal turnover. Leadership and Policy in Schools, 9, 367-383. doi:10.1080/15700763.2010.493633.

10.Miller, A. (2013). Principal turnover and student achievement. Economics of Education Review, 36, 60-72. doi:10.1016.2013.05.004.

11.National Center for Education Statistics. (2006). Early Childhood Longitudinal Study, Kindergarten class of 1998-99: Combined user's manual for the ECLS fifth-grade data files and electronic codebooks. Retrieved from http://www.nces.ed.gov/ecls.

12.Nettles, S., \& Petscher, Y. (2006, April). An examination of the relationship between the implementation practices of school principals and student achievement in reading. Paper presented at the annual American Educational Research Association. San Francisco, CA.

13.Papa, F., Jr. (2007). Why do principals change schools? A multivariate analysis of principal retention. Leadership and Policy in Schools, 6(3), 267-290. doi:10.1080/15700760701263725.

14.Partlow, M. C., \& Ridenour, C. S. (2008). Frequency of principal turnover in Ohio's elementary schools. MidWestern Educational Researcher, 21(2), 15-23.

15.Pijanowski, J. C., \& Brady, K. P. (2009). The influence of salary in attracting and retaining school leaders. Education and Urban Society, 42(1), 25-41. doi:10.1177/0013124509342952.

16.Slate, J. R., \& Rojas-LeBouef, A. (2011). Calculating basic statistical procedures in SPSS: A self-help and practical guide to preparing theses, dissertations, and manuscripts. Ypsilanti, MI: NCPEA Press.

17.Tekleselassie, A. A., \& Villarreal, P. (2011). Career mobility and departure intentions among school principals in the United States: Incentives and disincentives. Leadership and Policy in Schools, 10(3), 251-293. doi:10.1080/15700763.2011.585536

18.Marzano, R. J., Waters, T., \& McNulty, B. A. (2005). School leadership that works: From research to results. Alexandria, VA: Association for Supervision and Curriculum Development. 